\title{
Furtado e seus críticos: da estagnação à retomada do crescimento econômico *
}

\author{
Mauricio C. Coutinho ${ }^{* *}$
}

\begin{abstract}
Resumo
O artigo discute o 'modelo de estagnação', desenvolvido por Furtado em 1965 e 1966, e comenta a crítica de Tavares e Serra à formulação de Furtado, de 'Além da Estagnação' (1971). Procura discutir em que medida os textos de Furtado da primeira metade dos anos 1970 teriam representado uma meia-volta, no sentido de abandono dos pressupostos analíticos do modelo estagnacionista. Conclui que os impasses do modelo de estagnação de Furtado são inúmeros e bem diversos daqueles arguidos por Tavares e Serra.
\end{abstract}

Palavras-chave: Celso Furtado, 1920-2004; Modelo de estagnação; Relação capital/produto.

\section{Abstract}

Furtado and his critics: from stagnation to the recovery of economic growth

The article debates the 'stagnation model' proposed by Furtado in 1965 and 1966, and comments on Tavares and Serras's criticism of Furtado's model, in 'Beyond Stagnation' (1971). It also discusses to what extent Furtado's 1970s texts would have represented a change in opinion, in the sense of putting aside the analytical presuppositions of the stagnation model. It is argued that the dilemmas of Furtado's stagnation model are many, and quite different from those argued by Tavares and Serra.

Keywords: Celso Furtado, 1920-2004; Stagnation model; Capital/Output ratio. JEL B30, O54.

\section{Introdução}

Nos anos de 1965 e 1966, Celso Furtado desenvolveu um 'modelo de estagnação' voltado à explicação da significativa redução das taxas de crescimento nas economias latinoamericanas entre o final dos anos 1950 e o início dos anos 1960. Uma versão do modelo encontra-se no capítulo 3 (Fatores estruturais internos que impedem o desenvolvimento) do livro Subdesenvolvimento e Estagnação na América Latina, publicado em 1966 (Furtado, 1966a). Versões anteriores haviam sido publicadas na forma de artigo $^{1}$.

Além da análise do esgotamento do processo de substituição de importações, a apresentação do modelo de estagnação envolve uma reexposição do modelo histórico-

\footnotetext{
*Artigo recebido em 2 de agosto de 2017 e aprovado em 1 de agosto de 2018.

${ }^{* *}$ Professor do Instituto de Economia da Universidade Estadual de Campinas (IE/Unicamp), Campinas, SP, Brasil. Email: coutinho@unicamp.br.

(1) Furtado (1965b) e Furtado (1966b). Furtado e Maneschi (1968) apresenta uma variação do modelo estagnacionista. A terceira parte ('Evolução das estruturas econômicas Latino-Americanas') de A Hegemonia dos Estados Unidos e o Subdesenvolvimento da América Latina (Furtado, 1973) representa uma reedição, com modificações, do terceiro capítulo de Furtado (1966a).
} 
estrutural de Furtado, distinta em significativos detalhes de versões anteriores, inclusive da versão clássica de Formação Econômica do Brasil (Furtado, 1959). Os diversos capítulos do livro publicado em 1966 estendem-se ainda em temas diversos, que abrangem hipóteses sobre a estrutura social e os dilemas do sistema político brasileiro e uma crítica aberta ao populismo, às políticas conservadoras e às estratégias da esquerda. Poucos comentadores deram-se conta desse caráter amplo e integrado da obra, que, em conjunto com Teoria e Política do Desenvolvimento Econômico (Furtado, 1967), compõe uma espécie de binômio magnífico, representativo de um momento de grande produtividade acadêmica do autor.

O destino das duas obras foi bem distinto. Enquanto Teoria e Política - um sumário dos cursos de desenvolvimento econômico desenvolvidos em Paris - foi bem recebida por críticos e leitores, obteve longevidade editorial e sucessivas reedições, o impacto de Subdesenvolvimento e Estagnação foi de curta duração. Mais grave ainda: no início da década de 1970, o modelo estagnacionista veio a ser incluído no rol dos equívocos de Furtado, quando menos porque a economia brasileira voltara a crescer em 1967.

Talvez um dos maiores responsáveis pela imagem negativa associada à obra de 1966, e ao modelo estagnacionista em si, tenha sido a crítica efetuada por Tavares e Serra em 'Além da Estagnação. Uma discussão sobre o estilo de desenvolvimento recente do Brasil' (Tavares; Serra, 1971) - este sim, um artigo de ampla repercussão na América Latina e no Brasil ${ }^{2}$. Por precisão, assinale-se que a crítica de Tavares e Serra refere-se aos impasses do modelo de substituição de importações; a rigor, a apenas um segmento da argumentação contida nas diversas versões do modelo estagnacionista. Contribuições adjacentes e importantes, inclusive e principalmente a reelaboração e reexposição do modelo histórico de desenvolvimento brasileiro envolvendo a utilização do acelerador, não foram objeto da crítica. De todo modo, tudo indica que a abordagem estagnacionista de Furtado passou à memória intelectual brasileira mais pelas críticas de Tavares e Serrado que por seu conteúdo específico, em um daqueles casos, não raros, em que o comentário torna-se mais conhecido do que o comentado.

Para complentar a má sorte de Subdesenvolvimento e Estagnação, passou a circular nos círculos acadêmicos brasileiros após a publicação de Análise do Modelo Brasileiro (Furtado, 1972), a opinião velada de que esta obra, em conjunto com outras publicadas no período 1970/1974, em particular O Mito do Desenvolvimento Econômico (Furtado, 1974), representaria uma espécie de revisão ou rejeição da tese estagnacionista, ou até mesmo uma admissão tácita da validade da crítica de Tavares e Serra ${ }^{3}$. Em suma, para muitos, Análise do Modelo, o texto em que Furtado se propôs a explicar as razões da retomada do crescimento da economia brasileira após 1967, passou a ser visto, se não como uma retratação, ao menos como uma guinada teórica do autor.

(2) Tavares e Serra (1971) informam que uma primeira versão de seu texto foi apresentada em um seminário promovido por Unesco e Flacso em novembro de 1970.

(3) Essa maré de críticas ao modelo estagnacionista de Furtado não deixou muitos testemunhos editados. Um exemplar representativo encontra-se em Oliveira (1972) 
O objetivo do presente trabalho é duplo: revisar o modelo de estagnação e detectar os traços de continuidade entre o Furtado estagnacionista e o Furtado da primeira metade da década dos 1970. Sendo óbvio que mudara a economia brasileira, a questão é até que ponto o autor mudou; evidentemente, não no sentido de admitir o que era patente - a retomada do crescimento -, senão em dois outros e mais relevantes aspectos: a) transformações decisivas no método de análise histórico-estrutural e na visão geral do desenvolvimento latinoamericano; b) mudanças perceptíveis nos recursos de análise econômica utilizados, principalmente, uma eventual rejeição dos modelos baseados no acelerador, que fundamentam a hipótese estagnacionista.

O artigo desenvolve-se em quatro seções, afora esta Introdução. A primeira seção sumaria a tese estagnacionista de Furtado, recupera origens e aponta possíveis (e amplíssimos) impasses analíticos. A segunda efetua uma revisão pontual da crítica de Tavares e Serra. Advirta-se que o propósito não é discutir as imensas potencialidades de 'Além da estagnação' para o entendimento do desenvolvimento brasileiro, senão reconstituir o núcleo racional da crítica às (apontadas) inconsistências internas do modelo de Furtado. A terceira seção alinha argumentos em Análise do Modelo e Mito do Desenvolvimento Econômico que apontam para os elementos de continuidade entre estes textos e Subdesenvolvimento e Estagnação. Na última seção, as conclusões. Torna-se claro que a busca de continuidade, muito mais do que a admissão de uma ruptura no pensamento de Furtado, é o leitmotif do presente artigo.

\section{Alguns traços do modelo de estagnação}

Como procurei argumentar em trabalho anterior (Coutinho, 2015), Subdesenvolvimento e Estagnação (Furtado, 1966a) representa, no que diz respeito tanto ao reprocessamento do modelo histórico-estrutural quanto aos comentários sobre a situação econômica ao início dos anos 1960, uma introjeção plena do acelerador no esquema de análise de Furtado. É sabido que Furtado valera-se no modelo histórico clássico - por exemplo, o de Formação Econômica do Brasil (Furtado, 1959) - do multiplicador keynesiano e da identidade poupança-investimento ${ }^{4}$. No modelo de estagnação, o instrumento fundamental passa a ser a equação básica de equilíbrio dinâmico dos modelos de Harrod e de Domar, que relaciona a taxa de crescimento à relação capital/produto e a propensão a poupar. Enfim, no modelo estagnacionista, Furtado adiciona ao multiplicador o acelerador, e desenvolve considerações sobre a trajetória econômica da América Latina a partir do exame da relação capital/produto e da taxa de poupança e de investimentonas diversas situações históricas, do período primário-exportador ao (aparente) impasse do processo de substituição de importações.

$\mathrm{O}$ acelerador não representava um recurso analítico novo para o autor. Furtado relata na autobiografia (Furtado, 1989) que durante sua temporada em Cambridge, nos anos $1957 \mathrm{e}$ 1958, privou do círculo keynesiano e participou das acesas discussões em torno do modelo de

(4) Procurei detalhar estes pontos em Coutinho (2007). 
crescimento de Kaldor. Esteve presente, portanto, em uma das sucessivas rodadas do ciclo teórico suscitado pelo modelo de Harrod.

Por outro lado, na década de 1950 tornara-se um lugar comum a utilização da equação básica dos modelos de Harrod e de Domar nos exercícios de planejamento econômico aplicados aos países subdesenvolvidos ${ }^{5}$. Desenvolvimento e Subdesenvolvimento (Furtado, 1961) e Teoria e Política do Desenvolvimento Econômico (Furtado, 1967) trazem uma resenha desses exercícios. O livrinho Perspectivas da Economia Brasileira (Furtado, 1958) efetua uma exposição didáticada combinação entre multiplicador e acelerador e apresenta algumas simulações, sempre com o propósito de estimar o crescimento potencial da economia brasileira. Neste aspecto, Perspectivas da Economia Brasileira segue os manuais de planejamento econômico da Cepal, de cuja redação o próprio Furtado participara ${ }^{6}$. Em resumo, ao menos desde meados dos anos 1950, a interação entre multiplicador e acelerador era um assunto bem conhecido pelos economistas envolvidos em desenvolvimento e planejamento econômico, Furtado em particular.

Afora o acelerador, Subdesenvolvimento e Estagnação evidencia a incorporação da temática da grande empresa industrial internacional ao esquema de referências de Furtado. Em O Mito do Desenvolvimento Econômico (Furtado, 1974), assim como em sua autobiografia (Furtado, 1991), o autor se refere aos impactos dos contatos com Hymer, em sua temporada norte-americana ${ }^{7}$. Não é difícil perceber que entre os anos 1964-1966, a grande empresa internacional e suas características tecnológicas, organizacionais e de propriedade, penetram na abordagem histórico-estrutural de Furtado, até então desprovida de maiores considerações sobre empresas, estruturas de mercados, internacionalização, tecnologia ${ }^{8}$.

No presente trabalho vamos fazer referências apenas laterais às características inovadoras da reapresentação do modelo histórico-estrutural de Subdesenvolvimento e Estagnação, concentrando-nos na interpretação da crise dos anos 1960. Em termos sintéticos, pode-se dizer que, para Furtado, o processo de industrialização sem esgotamento do excedente populacional - portanto, com salários determinados pelos padrões vigentes no 'setor de subsistência' - estreita o mercado de consumo de massas para produtos da moderna indústria. Esta indústria, em grande parte internacionalizada e caracterizada pelas elevadas densidades de capital e por escalas mínimas eficientes das plantas substancialmente ampliadas, adota tecnologias adaptadas à produção em massa. Furtado sustenta que na América Latina tanto a indústria produtora de bens de consumo durável como a de bens de capital, transpostas a partir dos anos 1950 de acordo com os padrões tecnológicos vigentes nos países desenvolvidos,

(5) Hirschman (1958) faz referência à utilização da relação produto/capital e da propensão a poupar nos exercícios de planejamento econômico na América Latina, na década de 1950.

(6) Ver Furtado (1955). Embora não assinado, foi redigido por Furtado este capítulo do manual da Cepal com o cálculo da taxa de crescimento a partir da combinação entre multiplicador e acelerador.

(7) Furtado permanece nos Estados Unidos de setembro de 1964 a junho de 1965

(8) Tudo indica - ver Bianconi (2015) - que os seminários de que Furtado participou no ILPES, em Santiago, em 1964, após sair do Brasil, tinham como tema central o impacto das empresas internacionais na economia latino-americana. 
operam com baixa ocupação da capacidade instalada. A concentração de renda impede a criação de mercados de massa para seus produtos. Sua conclusão é de que, graças à elevada densidade de capital e à impossibilidade de utilização plena da capacidade, a relação produto/capital na indústria moderna seria baixa, inferior àquela que prevalecia na agricultura capitalista e, inclusive, no setor industrial tradicional, produtor de bens de consumo corrente. A expansão da indústria de bens de capital e de bens de consumo durável teria provocado, portanto, a contração da relação produto/capital média da economia, a qual, na ausência de devida compensação proporcionada pelo aumento da taxa de investimento, teria reduzido a taxa de crescimento.

Ainda de acordo com Furtado, a elevação da concentração de renda e as gigantescas margens de excedente da indústria moderna, propiciadas pela contenção dos salários, permitiram que em certas circunstâncias o aumento dos lucros, da poupança e do investimento, compensasse a queda na eficiência do capital. A tendência dominante, no entanto, teria sido o refreamento do crescimento econômico, em virtude da queda da eficiência do capital global; ou melhor, em virtude de uma queda da relação produto/capital não compensada por elevação suficiente da taxa de investimento.

Cabe assinalar que Furtado (1966a) é enfático na distinção entre os diversos países da América Latina. Além da diferenciação típica entre países com população e mercados de maiores dimensões - Brasil, Argentina e México - e países pequenos demais para levarem adiante a diversificação industrial, o modelo estagnacionista explora a diferença essencial entre países que esgotaram o excedente populacional (Argentina, Uruguai) e os que não esgotaram. Nos países com maior população e setor industrial significativo, em especial o Brasil, Furtado (1966a) admite que se possa levar adiante a diversificação industrial e a incorporação de segmentos modernos à estrutura produtiva. $\mathrm{O}$ tamanho absoluto do mercado viabilizaria a incorporação de indústrias modernas de bens duráveis e de bens de capital, assim como a modernização de parte da indústria de bens de consumo não-durável. Nessas circunstâncias, a diversificação prossegue em meio a dificuldades, sem possibilitar a superação da dualidade estrutural básica.

A manutenção da dualidade seria reforçada ainda pelo fato de a introdução de setores com elevada dotação capital/trabalho provocar queda da taxa de absorção de mão-de-obra pelos segmentos modernos da economia, assim como tendência ao agravamento da concentração de renda. Na visão do Furtado dos anos 1965-70, sem esgotamento do excedente populacional não há superação do subdesenvolvimento.

A bem da verdade, em Subdesenvolvimento e Estagnação, Furtado chega a concluir que, no caso brasileiro, a tendência à estagnação decorre da política: a estrutura política do país revelara-se incapaz de absorver de modo produtivo o clamor crescente das massas pobres, um impasse que envolve um conjunto de fatores, tais como elites atrasadas e pouco propensas à defesa de um projeto nacional de desenvolvimento, estruturas de representação viesadas e caducas, esquerda equivocada... Em resumo, impossibilidade de conduzir um projeto 
econômico transformador. Para Furtado (1966a), é bem claro que o impasse brasileiro de 1964 foi sobretudo politico, embora totalmente soldado a uma dinâmica econômica que levou à queda do ritmo de absorção da população em atividades de alta produtividade, assim reiterando a concentração de renda. A concentração de renda reforça o estreitamento de mercado para os produtos da indústria moderna, vindo a criar uma crônica dissociação entre moderna tecnologia (e produção em massa) e eficiência econômica.

Passando ao largo de uma revisão detalhada do modelo de estagnação ${ }^{9}$, é importante assinalar algumas particularidades, não isentas de dilemas, associadas ao uso do acelerador na modelagem econômica de Furtado dos anos 1965 e 1966. Em primeiro lugar, a literatura econômica costuma associar a combinação entre multiplicador e acelerador a modelos agregados, e não a modelos multi-setoriais, como o de Furtado. A utilização de 'eficiências do capital' segmentadas por setores de atividade econômica não é trivial. Se pensarmos no caráter geral dos modelos de crescimento econômico do pós-guerra, keynesianos ou neoclássicos, a idéia de uma relação capital/produto segmentada por setores e diferenciada não deixa de ser inusitada. Pode-se cogitar que talvez Furtado tenha sido levado a desagregar setorialmente a relação capital/produto por reportar-se ao quadro de ampla heterogeneidade estrutural da economia latinoamericana. De todo modo, a desagregação é um traço típico, e não desprovido de problemas, como veremos, do modelo de estagnação.

Ainda no terreno das inovações - das hesitações de Furtado, eu diria, -, o caráter da relação capital/produto oscila nas diversas abordagens: ora se trata de um dado 'estrutural', sujeito a variações no longo prazo, ora sofre alterações na proporção em que os investimentos se sucedem. Para Harrod, a relação capital/produto é 'estrutural', ou sujeita a variações no longo prazo, conforme o desenvolvimento da tecnologia. De modo análogo, a relação produto/capital aparece em estudos anteriores do próprio Furtado como um dado 'estrutural', de lenta mudança, sujeito à tecnologia. Esta é a perspectiva, entre outros textos, de Perspectivas da Economia Brasileira. Já nos textos estagnacionistas, as transformações da relação produto/capital passam a representar um fator ativo da dinâmica econômica, tanto no longo prazo como em períodos não muito largos. Não nos referimos aqui apenas às oscilações da relação produto/capital devidas às variações do grau de utilização da capacidade ao longo do ciclo, um ponto admitido por Harrod e também por Furtado. O modelo de estagnação vai adiante: refere-se a flutuações 'estruturais' na relação produto/capital, provocadas pela passagem da dominância econômica de um a outro setor, da agricultura primário-exportadora à indústria tradicional, da indústria de bens de consumo corrente à de bens de capital... Enfim, relação produto/capital segmentada e ativamente flutuante são características típicas do modelo de estagnação de Furtado.

Vale mencionar o considerável problema dos preços relativos. Como se sabe, as propriedades do modelo de Harrod ficam mais bem caracterizadas quando associadas a preços relativos constantes. Ora, os modelos histórico-estruturais de Furtado pressupõem variações de

(9) Tarefa empreendida em Coutinho (2015). 
preços relativos. Particularmente, a passagem do período primário-exportador ao de dinâmica orientada pelo mercado interno, bem como as sucessivas fases do processo de substituição de importações, são incompreensíveis fora de um quadro que contemple variações dos preços relativos. Aqui nos referimos não apenas às variações ditadas pelos constrangimentos cambiais e oscilações da taxa de câmbio, mas também e, sobretudo, às várias modalidades de proteção e subsídios cambiais e fiscais, característicos da industrialização latino-americana nos diversos países. Em suma, os constrangimentos cambiais e as proteções deles decorrentes, as políticas orientadas à construção ou desobstrução da infraestrutura, os múltiplos esquemas de financiamento subsidiados ou subindexados, subentendem alterações constantes dos preços relativos ${ }^{10}$. Nessas condições, flutuam incessantemente os preços relativos dos componentes do capital e dos diversos elementos do produto. Além disso, os equipamentos importados tanto podem ter seu valor afetado por proteção cambial e por financiamentos vantajosos, como, em especial em se tratando de importações intra-firmas, serem transferidos a preços (declarados) que nada têm a ver com o custo efetivo da internação. No modelo de estagnação, todas estas flutuações e preços 'ajustados' afetam não apenas o cálculo de rentabilidade das firmas, como a contabilização da relação produto/capital nos setores específicos de atividade econômica, uma vez que produto e capital são medidos em valores. Voltaremos a esse ponto, que marca um uso específico da relação produto/capital por Furtado.

Para complementar o quadro das indefinições do modelo de estagnação, assinale-se que Furtado trabalha com relação produto/capital média, assumindo assim a equivalência entre relação marginal e média, ou relação produto/capital marginal constante. Sabendo-se que os efeitos do acelerador estão associados à relação capital/produto marginal, como proceder em um caso - o das economias latino-americanas - em que a contínua variação de preços relativos impede que se cogite de estabilidade da relação capital/produto média? Em outras palavras, pode-se tomar a relação média como representativa da marginal?

Finalmente, vale salientar o caso especial do setor produtor de bens de capital. No modelo de Furtado, este é um dos segmentos de elevada dotação capital/trabalho e baixa relação produto/capital. Furtado admite que o encarecimento dos bens de capital, que é até mesmo pré-condição para sua produção local, vem a se constituir em um embaraço adicional à capitalização de todos os setores, uma vez que equipamentos caros contribuem para a elevação da relação capital/produto da economia, em caráter geral. Não sendo totalmente incorreto, o argumento deixa de assinalar o fato de que, no setor de bens de capital, o encarecimento dos equipamentos afeta tanto o numerador quanto o denominador da relação capital/produto específica (medida em valores). Vale dizer que não se pode concluir, em caráter preliminar, qual será o impacto da elevação do preço do produto final sobre a relação capital/produto neste setor.

(10) A variação de preços relativos, evidente no modelo clássico de Furtado (Furtado,1959), é destacada por bem poucos comentadores. De todo modo, Furtado (1972), bem como Furtado (1974) reforçam o papel da variação dos preços relativos. 


\section{A crítica de Tavares e Serra}

A crítica de Tavares e Serra não se circunscreve a qualquer dos pontos acima assinalados ${ }^{11}$. A rigor, pode-se dizer que ela tem como elemento nuclear a contestação à hipótese de nivelamento da taxa de lucros dos diversos setores industriais, adotada por Furtado no modelo estagnacionista. $\mathrm{E}$, de fato, ao comentar as diferenças entre os setores $\mathrm{P}_{4}$ (bens de consumo corrente) e $\mathrm{P}_{5}$ (bens de consumo durável e de capital), bem como os impactos da internalização de $\mathrm{P}_{5}$ sobre as relações capital/trabalho e produto/capital, Furtado (1966a) afirma que a homogeneidade da taxa de lucro é pré-condição para o investimento nos diversos setores da indústria ${ }^{12}$.

A contestação de Tavares e Serra à hipótese de nivelamento da taxa de lucros apóia-se nas modernas teorias do oligopólio, que admitem diferenciais de lucros entre os setores da indústria. Os dois críticos complementam a demonstração das inconsistências internas do modelo de Furtado com o recurso à 'taxa de exploração', da tradição marxista. A elevação desse excedente sobre os custos salariais, um resultado típico de indústrias intensivas em capital, explicaria a possível elevação dos lucros, mesmo em situação de queda da relação produto/capital.

Preliminarmente, e antes de entrarmos na 'taxa de exploração', vale notar que basta a admissão de uma taxa de lucro não necessariamente homogênea para minar a hipótese, sustentada em Furtado (1966a), de que a elevação da relação capital/trabalho, em condições de uniformidade da taxa salarial, implica declínio da relação produto/capital. Tavares e Serra (1971) afirmam que a correspondência entre aumento da densidade do capital e elevação da relação capital/produto está associada “... a um esquema analítico de corte neoclássico, de equilíbrio geral...” (Tavares; Serra, 1971, p. 914), que não consideraria os efeitos do progresso técnico que acompanha a acumulação de capital ${ }^{13}$.

Deixando para as conclusões comentários mais específicos sobre o 'corte neoclássico' do modelo de estagnação, é possível afirmar que a suposição de uma taxa de lucro uniforme parece responder a uma necessidade mais simples do modelo. Em suma, e antecipando algumas conclusões, acredito que a imposição de uniformidade da taxa de lucro por Furtado (1966a) foi instrumental à demonstração de que a uma elevação da densidade de capital corresponde uma queda da relação produto/capital, nas especiais condições da industrialização latino-americana.

Com efeito, basta explicitarmos a taxa de lucro bruto

$$
r=\frac{P-L}{K},{ }^{14}
$$

(11) Tavares e Serra (1971) referem sua crítica a uma versão de Furtado (1966b) incluída em Bianchi (1969).

(12) Significativamente, na reedição do capítulo 3 de Subdesenvolvimento e Estagnação (Furtado, 1966a) que aparece como Terceira Parte (Evolução das estruturas econômicas Latino-americanas) de A Hegemonia dos Estados Unidos e o Subdesenvolvimento da América Latina (Furtado, 1973), o parágrafo que postula a igualdade da taxa de lucro inter-indústrias foi suprimido. Devo esta observação a Renata Bianconi.

(13) Rodriguez (2009) é mais claro e propõe que, nesse aspecto, Furtado assume uma função de produção neoclássica.

(14) Notar que se trata de uma versão simplificada da taxa de lucro, na qual no numerador temos somente o que Furtado (1996a) denomina de 'lucro bruto', ou valor do produto menos custo do trabalho. 


$$
\text { como } r=\frac{P}{K}-\frac{L}{K}
$$

onde $r$ é a taxa de lucro bruto; $P$, o produto; $L$, custo em trabalho; $K$, capital;

para verificarmos que, mantida a taxa de lucro (r) constante nos diversos setores da indústria, a qualquer elevação de $K / L$ (diminuição de $L / K$ ) corresponderá redução proporcional de $P / K$. É desnecessário sustentar, ou presumir, hipóteses adicionais sobre progresso técnico e funções de produção. O resultado proposto por Furtado depende inteiramente de taxa de lucro uniforme. Uma vez que Furtado (1996a) assume que os segmentos modernos da indústria - bens de capital e bens de consumo durável - envolvem uma dotação de capital por trabalhador muito superior à da indústria tradicional, a hipótese de manutenção da taxa de lucro é suficiente para que se chegue à conclusão de que a introdução e expansão de tais setores implica uma redução da relação produto/capital setorial e global.

A admissão alternativa de que a taxa de lucro dos segmentos mais capital intensivos é superior à da indústria tradicional levaria a que uma elevação de $\mathrm{K} / \mathrm{L}$ não necessariamente correspondesse a uma queda de $\mathrm{P} / \mathrm{K}^{15}$. Em suma, o motivo de Furtado manter a hipótese, forte e de outro modo ininteligível, de homogeneidade da taxa de lucro, parece ser a necessidade de vincular elevações da densidade do capital à queda da relação produto/capital ${ }^{16}$.

Caso não se adote o requisito de homogeneidade da taxa de lucro, sempre se pode imputar às firmas em $\mathrm{P}_{5}$ uma taxa de lucro superior o bastante para contrarrestar a presumida interconexão entre elevação de K/L e redução de P/K. Como mencionado, Tavares e Serra (1971) - assim como Rodriguez (2009) -relacionam a elevação da taxa de lucro aocomportamento do excedente sobre os custos salariais, maior nos setores mais intensivos em capital. Tavares e Serra (1971) referem-se especificamente ao aumento da 'taxa de exploração', ou taxa de mais-valia, representada por

$$
m=\frac{P-w}{w}
$$

onde Pé o produto por trabalhador e $w$ o salário unitário. Se introjetarmos a taxa de exploração na fórmula da taxa de lucro (a mesma utilizada por Furtado), chegaríamos, de acordo com Tavares e Serra, a

$$
r=\left(\frac{P}{K}\right) * \frac{m}{m+1}(4)^{17}
$$

(15) O exemplo de Furtado utiliza os seguintes valores para P4 e P5: em P4(indústria tradicional), K/P=1, K/L=2500, $\mathrm{P}=2500$ e $\mathrm{L}$ (custo salarial)=600. Neste caso, a taxa de lucro é $76 \%$. Admitindo-se em P5(indústria de bens de capital e de consumo durável) o mesmo salário, a mesma taxa de lucro e uma relação $K / L=10.000, P / K$ equivaleria a 0,82 . Se relaxarmos a hipótese de igualdade da taxa de lucro, uma elevação da relação K/L equivalente à do exemplo de Furtado levaria a taxa de lucro em P5 a $94 \%$, mesmo que se mantenha a relação $\mathrm{P} / \mathrm{K}$.

(16) Como foi dito (ver nota 12), na reedição do capítulo 3 de Furtado (1996a) em Furtado (1973) as diversas referências à homogeneidade da taxa de lucro foram suprimidas.

(17) Em Tavares e Serra (1971), esta formula aparece como $r=a * \frac{m}{m-1}$, onde $a=P / K$. Um evidente erro, corrigido em Tavares e Serra (2000) para $r=m * \frac{m}{m+1}$, aqui utilizada. 
Com efeito, basta desenvolvermos (4) para a taxa de mais-valia para obtermos

$$
r=\frac{P}{K} * \frac{P-w}{w} * \frac{w}{P-w+w} \quad \text { ou ainda a } \quad r=\frac{P}{K} * \frac{P-w}{P}
$$

e afinal

$$
r=\frac{P-w}{K}
$$

o que nos leva de volta à fórmula de Furtado, se $P$ for considerado o produto total (e não o produto por trabalhador) e $w$ o equivalente a salário total, ou despesa com trabalho (o $L$ de Furtado).

Pode-se perceber de (4) que uma elevação da taxa de mais-valia afetará positivamente a taxa de lucro, considerando-se a manutenção da relação $P / K$. Uma elevação de $P / K$, naturalmente, reforçaria a elevação da taxa de lucro. O mais interessante, porém, é que uma pequena redução de $P / K$ afeta negativamente a taxa de lucro, bem mais do que qualquer substancial elevação da taxa de mais-valia. A explicação é simples: a razão $m /(m+1)$ converge - e rapidamente - para 1, para valores crescentes de $m$. Nessas condições, embora os efeitos das variações de $P / K$ e de $m$ sobre a taxa de lucro $(r)$ dependam crucialmente dos valores inicialmente assumidos para ambos os termos, bem como da velocidade de suas variações - ou seja, dos valores assumidos por $P / K$ e $m$ nas situações concretas -, a possibilidade de que aumentos da taxa de mais-valia compensem quedas da relação produto/capital é limitada.

Tomemos os seguintes exemplos: sendo $\frac{P}{K}=\frac{1}{5}$ e $m=5$, requivalerá a $16,6 \%$. Uma duplicação da taxa de mais-valia $(m=10)$, com manutenção da relação $P / K$, elevaria a taxa de lucro a $18,2 \%$. Já uma pequena redução da relação $P / K$, de $1 / 5$ para $1 / 6$, mantida a taxa de mais-valia em 10, reduziria a taxa de lucro a $15,2 \%$. Os exemplos sugerem que: a) a elevação da taxa de mais-valia, por si só, afeta pouco a taxa de lucro; b) os efeitos de uma elevação substancial da taxa de mais-valia são contrarrestados por reduções não muito expressivas da relação produto/capital.

Tavares e Serra (1971) afirmam que Furtado preferencialmente assume progresso técnico poupador de mão-de-obra, sendo pouco atento ao progresso técnico poupador de capital. Eu não tenho tanta certeza disto, e há evidências textuais de que Furtado (1966a) admite produtividade do trabalho e do capital maiores em $\mathrm{P}_{4}$ (indústria de bens de consumo corrente) do que em $\mathrm{P}_{2}$ e $\mathrm{P}_{3}$ (setores de agricultura capitalista). Penso que o mesmo se aplica a $\mathrm{P}_{5}$ versus $\mathrm{P}_{3}$.

De todo modo, e para reforçar a inconsistência do modelo de Furtado, Tavares e Serra (1971) afirmam que, mesmo admitindo-se progresso técnico poupador de mão-de-obra, a relação produto/capital só cairá se o aumento relativo da produtividade do trabalho for menor 
do que o aumento relativo da dotação de capital por trabalhador ${ }^{18}$. E, neste caso, ainda que se admita o declínio da relação produto/capital, o aumento da taxa de mais-valia pode provocar um aumento do 'excedente a ser invertido'.

Ora, se entendermos que o 'excedente a ser invertido' espelha a taxa de lucro ${ }^{19}$; há, conforme foi visto, claros limites a tal compensação. Em outras palavras, mesmo elevações significativas da taxa de mais-valia podem não ser capazes de contornar os efeitos depressivos sobre a taxa de lucro de uma queda da relação produto/capital relevante. Da conclusão de Tavares e Serra

...ou a relação produto/capital não declina, apesar do aumento do coeficiente capital/trabalho, ou, se o faz, seus efeitos negativos sobre o excedente a ser invertido podem ser contrabalançados por um aumento do excedente subtraído à força de trabalho (Tavares; Serra, 1971, p. 914).

pode-se afirmar que a primeira proposição é verdadeira; a segunda, não necessariamente.

Se este excedente virá a ser invertido é outra questão, conforme Tavares e Serra (1971). De todo modo, para estes autores, a relação produto/capital é 'um resultado do processo econômico' e 'não faz parte dos cálculos empresariais'. O investimento depende sempre da taxa de lucro esperada. Minha impressão é de que em nenhum momento Furtado (1996a) considera a relação capital/produto um elemento da decisão empresarial. O que interessa aos empresários são os lucros a serem obtidos, que se manifestam na taxa de lucro. Estes lucros serão convertidos em investimento sempre que houver uma expectativa favorável em relação à evolução da taxa de lucro. Neste ponto, ou quanto aos fundamentos das decisões de investimento, não há razão para acreditar que haja grande dissonância entre Tavares e Serra e Furtado.

De todo modo, para Furtado, o excedente (o lucro) converte-se em 'poupança', e esta em investimento. Tavares e Serra possivelmente não assumiriam esta relação entre poupança e investimento - para eles, o investimento não se subordina à poupança prévia. Teríamos aqui uma verdadeira diferença de enfoque na interpretação da economia, de modo geral, e das vicissitudes do ciclo depressivo dos anos 1960, assim como de sua recuperação. A visão de Furtado sobre o investimento permanece presa a um modelo básico que envolve a interação multiplicador-acelerador e a identidade poupança-investimento, sempre assumindo precedência de poupança em relação a investimento. Admitindo que Tavares e Serra têm uma visão diferente sobre poupança e investimento, vale notar que entraríamos aqui na discussão das diferenças substantivas de interpretação da economia, saindo do plano específico da lógica e das contradições internas do modelo de Furtado, que é o que foi arguido por Tavares e Serra.

(18) O que se torna claro se desdobrarmos a relação $P / K$ em produtividade do trabalho e relação trabalho/capital, ou $\frac{P}{K}=$ $\frac{P}{T} * \frac{T}{k}$. Utilizo aqui $T$ para designar trabalho, para evitar confusões com o $L$, utilizado acima, que se aplica, como em Furtado (1966a), adespesas com o fator trabalho. Volto depois a este tema, ou seja, valores expressos em coeficientes técnicos ou em valor. (19) Tavares e Serra referem-se a 'excedente a ser invertido' como 'produto por unidade de insumo capital mais trabalho'. Como foi visto (nota 12), o 'lucro bruto' de Furtado inclui como insumo apenas o trabalho. 


\section{Furtado crítico de Furtado?}

Furtado discute as características da economia brasileira sob o governo militar em Análise do Modelo Brasileiro. Nesta obra o tom marcadamente pessimista de Subdesenvolvimento e Estagnação viu-se atenuado, talvez pelo simples fato de se estar diante da retomada efetiva do crescimento econômico a partir de 1967. Por isso, e também por reconhecer que a 'concentração dinâmica' de renda em favor das classes médias altas, favoreceu a expansão da demanda de bens duráveis e a retomada do crescimento econômico. Análise do Modelo foi tomado por muitos como a obra em que Furtado admite as virtudes expansivas de políticas concentradoras -reconhecendo, portanto, a validade de uma das proposições centrais do ensaio de Tavares e Serra. Neste comentário deixarei de lado tais preocupações - as obras do início da década dos 1970 representam uma meia-volta de Furtado? - para me concentrar no instrumental teórico e nos argumentos do autor à época. O objetivo principal é assinalar a reiteração de fórmulas analíticas já conhecidas, bem como a introdução de novos temas na análise do desenvolvimento econômico brasileiro.

Convém iniciar pelos usos da categoria nuclear da análise estagnacionista, a relação produto/capital. Furtado em momento algum deixa de assinalar que a taxa de crescimento, presente ou potencial, é um resultado da interação de relação capital/produto e taxa de investimento (ou de poupança). Em Análise do Modelo, afirma que, dado o valor histórico da relação produto/capital $(0,35)$, a taxa de investimento de $17 \%$ (a taxa média e pouco oscilante da economia brasileira) implica um crescimento anual de 6\%. Esta taxa representaria o horizonte de longo prazo da economia brasileira; sua superação a partir de 1967 teria decorrido de uma maior utilização da capacidade ociosa da indústria de bens de consumo durável. A ocupação de capacidade até então subutilizada, por sua vez, teria expandido lucros e elevado a poupança e a capacidade de investimento das empresas industriais. O movimento seria de curto prazo, e não permanente, simplesmente porque a efetivação de investimentos traria a relação produto/capital a seu patamar médio de longo prazo, e a taxa de crescimento ao nível de $6 \%$. Em resumo, para Furtado, a relação capital/produto oscila, conforme a maior ou menor ocupação de capacidade; porém, sempre em torno de seu nível estrutural. O mesmo ocorre com a taxa de poupança e de investimento ${ }^{20}$.

Trata-se então de analisar os fatores que permitiram a maior utilização da capacidade e uma pequena elevação da taxa de investimento, após o triênio inicial do governo militar. Furtado enfatiza a política agressiva de crédito ao consumo e as medidas ativas de transferência de renda para as classes médias altas, que teriam permitido a expansão da demanda por bens duráveis elevado à retomada do crescimento. Destacaainda a recuperação da capacidade de investimento do governo, propiciada pelas reformas nos sistemas tributário e de financiamento público. Sem esta retomada do investimento público, a taxa de investimentos teria permanecido a níveis inferiores aos padrões históricos da industrialização brasileira.

(20) O mesmo raciocínio é apresentado em O Mito do Desenvolvimento Econômico (Furtado, 1974), particularmente nos capítulos II e III (este último, conforme o prefácio, de redação quase concomitante à de Análise do Modelo). 
De todo modo, tanto em Análise do Modelo quanto em O Mito do Desenvolvimento, Furtado não deixa de atribuir um caráter 'estrutural' à retração da taxa de crescimento da indústria observada ao início dos anos 1960. Para ele, é a natureza do próprio processo de substituição de importações que explica a retração. Ao bloquear o consumo de massas, o processo substitutivo entorpeceu a difusão dos produtos, favorecendo antes a diversificação do consumo por parte de uma pequena elite. A dimensão restrita do mercado para os produtos consumidos pela população de altas rendas não permitiria a obtenção das economias de escala que caracterizam o potencial tecnológico da indústria moderna. Em suma, a desconexão entre progresso técnico e difusão dos produtos, uma característica da industrialização subdesenvolvida teria sido, no limite, o responsável pela retração econômica.

O Mito do Desenvolvimento desenvolve o tema e acrescenta novas dimensões ${ }^{21}$. $\mathrm{Na}$ realidade, o processo de substituição de importações viria a aprofundar um traço que provém do período primário exportador: a existência de duas cestas de consumo. A cesta da pequena elite emula o padrão de consumo dos países centrais, sendo crescentemente penetrada por bens duráveis. Antes importada, esta cesta passa ao final dos anos 1950 a ser paulatinamente produzida no Brasil, de preferência por empresas estrangeiras. Já a cesta de consumo da imensa população pobre contém produtos agrícolas e bens industriais pouco diversificados, de produção local. Na visão de Furtado, os bens industriais da cesta de consumo da população de baixa renda envolvem pouco progresso técnico, enquanto a cesta da elite envolve inovação de produtos. Vale lembrar que, no caso dos países subdesenvolvidos, o custo de oportunidade da introdução de novos produtos é pequeno, já que se trata de transferência, muitas vezes intraempresas, de produtos e processos produtivos recorrentemente criados nas economias centrais. De todo modo, o resultado é a introdução nos países subdesenvolvidos de processos produtivos capital-intensivos, tecnologicamente atualizados e suscetíveis a economias de escala. Como sabemos, é exatamente o elevado nível de capacidade ociosa, provocada pelo pequeno tamanho de mercado para bens sofisticados e inovadores, que provoca elevação da relação capital/produto.

Trata-se - acrescenta Furtado em O Mito do Desenvolvimento - de um processo de crescimento no qual o consumo de uma pequena faixa no topo da pirâmide de rendas comanda a internação da inovação tecnológica, pressiona o balanço de pagamentos, canaliza o excedente econômico para o consumo suntuário (e não para a acumulação) e, afinal, provoca uma permanente pressão sobre os salários dos trabalhadores industriais, exatamente para que a elite possa dispor de um excedente a ser gasto em bens modernos. Em outras palavras, a estrutura de consumo comanda um processo de acumulação que não incorpora a população pobre aos ganhos de produtividade, e que, ademais, tolhe o crescimento econômico, ao elevar a relação capital/produto.

(21) A disjunção entre inovação e difusão de novos produtos e tecnologias é um tópico que remonta no mínimo à Economia Brasileira (Furtado, 1954). 
Em Análise do Modelo, Furtado se refere ao 'anel de feedback fundamental' das economias desenvolvidas, que encadeia progresso técnico, crescimento da produtividade, crescimento proporcional dos salários, incorporação do grosso da população ao consumo dos bens da indústria moderna e, portanto, pleno aproveitamento das economias de escala e máxima eficiência econômica ${ }^{22}$. Nos países subdesenvolvidos, não se formam os 'automatismos básicos' que articulam de modo virtuoso acumulação e demanda. Esta 'insuficiência do anel de feedback fundamental' promove redução do crescimento e estagnação. O 'modelo' brasileiro operado pelos governos militares nada mais teria representado do que uma "tentativa de correção dessa insuficiência, mediante adaptação da demanda à estrutura de oferta ... e uma ação mais ampla do Estado na geração de empregos" (Furtado, 1972, p. 66)

Há nessas ponderações sobre o 'anel de feedback fundamental' três elementos básicos. Um deles é a reiteração da tendência à estagnação, ou do retardamento do crescimento. O outro é a insistência no papel do estado na geração de empregos, uma vez que o investimento industrial leva a uma absorção reduzida, ou insuficiente, de trabalhadores. O terceiro elemento é a atuação de mecanismos de adaptação da oferta à demanda; ou, no caso, e uma vez que a estrutura de oferta é rigidamente determinada pela tecnologia e provoca baixa absorção de trabalhadores nos setores modernos, de readaptação da demanda à estrutura de oferta, mediante concentração de renda em benefício da alta classe média.

Em suma, Furtado não abandona os exercícios de delimitação do crescimento potencial baseados na interação entre acelerador e taxa de investimento, nem deixa de buscar na adaptação (ou inadaptação) de oferta a demanda o ângulo preliminar de apreciação do desempenho das economias. A ruptura conceitual entre Subdesenvolvimento e Estagnação e os textos do início dos anos setenta é muito tênue. Em outros termos, os novos temas e desenvolvimentos trazidos pelos trabalhos do início dos anos setenta não deixam de ser compatíveis com variantes da abordagem histórico-estruturalapresentadas em textos de anos anteriores, especialmente Subdesenvolvimento e Estagnação.

Três destes desenvolvimentos merecem menção especial. Um deles, já mencionado, é a insistência no papel do estado na garantia da taxa mínima de investimento, bem como da oferta de emprego em ocupações urbanas. Acredito que este último ponto - dependência do emprego urbano ao investimento e às políticas públicas - não havia sido explorado nos textos pré-1970 de Furtado.

O segundo é uma maior explicitação da temática tecnológica e da distinção entre inovação e difusão, assim como uma especificação mais clara da atuação das empresas multinacionais. Pode-se dizer que Furtado passa nos textos dos anos 1970 a se preocupar com

(22) "Chamamos de anel de feedback fundamental a interação que existe entre o fluxo de salários e o crescimento da produtividade do trabalho; trata-se, em última instância, de interação entre as forças sociais que disputam os incrementos do produto e o progresso tecnológico que é a causa última desses incrementos” (Furtado, 1972, p. 65). 
os mecanismos de criação e difusão de tecnologia, e com suas implicações sobre o subdesenvolvimento ${ }^{23}$.

O terceiro mecanismo, finalmente, diz respeito ao refinamento da visão sobre a composição do grupo de consumidores de elite, bem como sobre as subdivisões no proletariado urbano. Em Análise do Modelo e em O Mito do Desenvolvimento, bem mais do que em textos anteriores, Furtado retira o operariado das modernas indústrias da massa indefinida de trabalhadores na base da pirâmide de rendas, e procura ainda distinguir seus rendimentos dos rendimentos de base - estes sim, claramente delimitados pela oferta ilimitada de mão-de-obra.

No entanto, e como visto acima, assim como não somente fatores estruturais estiveram em jogo na retração da taxa de crescimento no Brasil do início dos anos 1960, diversos fenômenos circunstanciais, ou de conjuntura, teriam atuado na retomada do crescimento produzida a partir de 1967. Dentre os fatores que contribuíram para a desaceleração do crescimento, e mesmo para a desorganização da atuação do estado, Furtado dá destaque à reforma cambial de 1961, que teria provocado perda de receita pública e, indiretamente, aceleração da inflação. Por sua vez, a crise econômica teria adquirido componentes de autorealimentação, devido à justaposição dos desajustes provocados pela inflação: desarticulação das poupanças das classes médias, embaraços nos balanços empresariais e no cálculo da renda tributável, desorganização dos instrumentos de financiamento ao consumo e à habitação.Se adicionarmos a este quadro a crise cambial, teremos alinhados os principais componentes da deterioração econômica e política do início da década de 1960.

De modo simétrico, a saída da crise exigiria redefinições das condições de financiamento público, a obtenção de certa tranquilidade no front cambial e, afinal, a reativação - mediante financiamento ou políticas de renda - do consumo de bens duráveis. Enfim, Furtado recorre ao (importante) varejo das circunstâncias de conjuntura e da política econômica, para explicar tanto o mergulho na crise quanto a estabilização e a posterior recuperação da economia.

Resta incluir uma breve menção à visão de Furtado a respeito de duas questões importantes para o entendimento do processo econômico em curso ao início dos anos 1970, bem como das prospecções sobre o futuro da economia brasileira. São elas a natureza do processo de concentração de renda em favor dos segmentos no topo da pirâmide de rendas, e as possibilidades de continuidade de um modelo de crescimento a tal ponto concentrador. Furtado não tem dúvidas de que a recuperação do crescimento decorreu diretamente das políticas abertas ou veladas de transferência de renda e de capacidade de gasto às classes médias altas, as quais teriam permitido a ocupação de capacidade ociosa da indústria moderna e exercido um impacto favorável sobre a economia, de modo geral. Questão em aberto é se a retomada do crescimento econômico permitiria, por si só, uma dinâmica de emprego favorável

(23) E aqui incluímos não apenas Análise do Modelo e O Mito, como também Prefácio a Nova Economia Política (Furtado, 1976) e Criatividade e Dependência na Civilização Industrial (Furtado, 1978). 
à absorção de mão-de-obra em segmentos modernos e formalizados da economia, condição indispensável à superação do subdesenvolvimento.

No que se refere à transferência de renda em favor de um segmento de rendas e/ou salários elevados, Furtado adverte a respeito dos impactos de um eventual crescimento dos salários reais sobre a estrutura de custo das empresas. Na verdade, e de modo um tanto surpreendente, o fenômeno da concentração de renda é visto não tanto como o fortalecimento de uma espécie de elite assalariada, quanto como a criação de um segmento de rentistas, ou de detentores de rendas mistas ('semi-rentistas' é a expressão utilizada), alimentados por benefícios fiscais e/ou por distribuição de dividendos. Vale lembrar que os incentivos fiscais à capitalização das empresas criaram uma legião de novos acionistas, assim como a nova política trabalhista criou uma legião de detentores de direitos sobre fundos fiscais (o FGTS). Os rendimentos propiciados pela detenção de fundos patrimoniais diversos teriam fomentado a demanda de bens de consumo durável.

No que se refere à continuidade do crescimento e à natureza do regime, Furtado pondera que o governo militar teria criado uma variante de 'capitalismo de estado', que requer cuidadosa articulação entre a classe empresarial e os poderes públicos. Este 'capitalismo de estado' não produz automatismos virtuosos, por falta de mecanismos automáticos para manutenção da demanda de bens de consumo a um nível adequado.

De acordo com Furtado, a criação de emprego dependerá neste modelo sempre da atuação do estado. O caráter progressista de uma política de emprego que retira os trabalhadores da marginalidade vê-se contrastado pela concentração de renda em benefício do quintil superior e pela consequente manutenção de uma enorme distância social. Enfim, na estrutura social brasileira inexistiriam canais permanentes de ascensão social. Cria-se um fosso entre o novo baronato e uma 'pequena classe média', composta por aqueles que saíram da marginalidade, mas não podem sonhar com ascensão social contínua. Acentua-se uma 'deformação social' que está longe de se assemelhar ao verdadeiro desenvolvimento econômico. O resultado é uma 'economia industrial subdesenvolvida' incapaz de instaurar o 'anel de feedback fundamental' característico do processo de desenvolvimento nas economias centrais. Sem a criação do 'anel de feedback fundamental', o processo de crescimento econômico pende sempre por um fio.

\section{Conclusões}

Interpretado em um sentido amplo, o esquema analítico de Furtado não sofreu rupturas decisivas entre o modelo estagnacionista dos anos 1960 e os textos do início da década de 1970. Simplesmente, Furtado procurou por-se em dia com a retomada do crescimento econômico e com fenômenos como o fortalecimento e liderança das empresas multinacionais, a natureza de um modelo econômico em que o investimento público ainda é decisivo e no qual o estado atua fortemente para garantir o emprego urbano e conformar uma estrutura de demanda solidária à oferta industrial. A continuidade analítica se evidencia em tópicos bem característicos, como a 
utilização da combinação de acelerador e taxa de poupança como a medida do crescimento efetivo e potencial da economia, a atenção às relações entre distribuição de renda e estrutura de demanda. A permanente busca dos descompassos - ou da recomposição do equilíbrio entre oferta e demanda permanece um traço fundamental da análise econômica de Furtado.

Evolução significativa - embora não ruptura - houve em diversos outros pontos, os quais, ou caracterizam o desdobramento de antigas interrogações, ou a adição de novos ângulos de aproximação à visão tradicional de Furtado sobre o subdesenvolvimento latino-americano. Um deles é a atualização da abordagem dos constrangimentos assegurados pela existência de um excedente populacional que não caminha para a extinção. Outros são a distinção entre inovações tecnológicas e difusão de novas tecnologias; os dilemas impostos por um mercado de trabalho que não permite massificar o consumo dos bens produzidos pela indústria inovadora; de modo associado, a coexistência de cestas de consumo distintas.

Em Análise do Modelo e em Mito do Desenvolvimento, Furtado procura caracterizar melhor a formação, a natureza e a realimentação de uma classe média alta que constitui o mercado por excelência para os bens de consumo durável. Além disso, busca distinguir com maior nitidez piso salarial das ocupações urbanas modernas e renda de subsistência da população extremamente pobre. Enfim, procura penetrar nas características de uma estrutura social que evolui e enfrenta diferenciações bem mais complexas do que as do passado, em que a simples contraposição de uma pequena elite à massa da população pobre representava uma descrição razoável da realidade. É controverso se a noção de 'semi-rentistas' caracteriza adequadamente essa nova elite; de todo modo, Furtado procura incorporar a seu esquema de análise a diferenciação da estrutura de rendas e de ocupações, a qual não se teria processado em um sentido virtuoso ou integrador, senão, possivelmente, ainda mais discriminador. Assinale-se que se passa a dar atenção também a um tema que, não inteiramente omitido, havia sido apenas tangenciado em Subdesenvolvimento e Estagnação: as estruturas de financiamento do consumo, do investimento e da construção civil compatíveis com as taxas de inflação elevadas e com os diversos regimes monetários e cambiais.

Assinaladas as diferenciações, cabe observar que a análise econômica de Furtado nos anos 1970 ainda mantém como elementos centrais a interação entre multiplicador e acelerador, a precedência da poupança em relação ao investimento, a permanente atenção à compatibilização entre oferta e demanda, os constrangimentos cambiais e fiscais. Isso para não falarmos da reiteração da atenção às pressões inflacionárias associadas aos desajustes cambiais e fiscais, bem como da preocupação em relação ao pequeno aparelhamento do estado diante da profusão de desafios de política econômica, temas não propriamente novos e que podem ser identificados - no contexto dos anos 1950 - em textos como Economia Brasileira (Furtado, 1954).

Admita-se, no entanto, que, embora Furtado continue a recorrer à combinação entre acelerador e taxa de poupança para o cálculo do crescimento efetivo e potencial, bem como a ressaltar os impactos das flutuações do grau de utilização da capacidade sobre a lucratividade 
da indústria, em ao menos um aspecto, os textos dos anos 1970 se afastam de uma característica crucial do modelo de estagnação: as diferenciações da relação produto/capital entre setores, com seus impactos sobre a dinâmica econômica.

Minha impressão - mais uma cogitação do que uma evidência documentada - é de que o modelo de estagnação tropeçou diante de suas ambiguidades e excessivas exigências analíticas, muito mais do que diante das críticas de Tavares e Serra. Para resumir o fundamental, e conforme apontado na seção 1, uma abordagem inspirada nas condições harrodianas de equilíbrioacomoda-se melhor a modelos de preços relativos constantes, enquanto o sistema de Furtado, em especial sua explicação para a evolução da industrialização latino-americana, assume (e depende de) variações de preços relativos. Tanto os constrangimentos cambiais quanto os diversos esquemas ad hoc de proteção setorial baseados em mecanismos cambiais, típicos da industrialização latino-americana, implicam flexibilidade de preços relativos.

Se somarmos à proteção cambial outros fatores de impulsão à indústria, como políticas de crédito favorecido em um ambiente inflacionário, com mais razão se poderá inferir que o suposto de taxa de lucro homogênea para aplicações de capital na indústria é irreal. Por outro lado, a flexibilidade de preços relativos e os diversos (e diferenciados) esquemas de proteção à indústria fazem com que a relação produto/capital marginal e a média não convirjam, havendo até mesmo certa impossibilidade de se estabelecer a relação produto/capital marginal, principalmente - e como foi visto - no setor de bens de capital.

Para concluir, uma palavra sobre funções de produção, densidade de capital e relação produto/capital, uma vez que Tavares e Serra (1971) e Rodriguez (2009) imputam ao modelo de estagnação de Furtado a admissão de uma abordagem neoclássica, ou até mesmo de uma função de produção neoclássica. Se devêssemos identificar uma função de produção nas diversas passagens em que Furtado se estende sobre a indústria moderna, inclusive na apresentação do modelo estagnacionista, ela seria de tipo Leontief: na América Latina, a indústria simplesmente adota a tecnologia em vigor nos países líderes, a despeito do baixo nível de salários. A adaptabilidade tecnológica é quase inexistente nos setores de bens de capital e de consumo durável. Em suma, baixa ou nula substituibilidade de fatores, a despeito dos diferenciais (e das possíveis variações) de preços relativos e das diferenças de ambiente econômico em relação aos países em que as tecnologias foram formuladas.

Por outro lado, nos diversos exemplos de que se vale ao longo da apresentação do modelo de estagnação, Furtado (1966a) representacapital, trabalho, produto, em valores expressados monetariamente (preços x quantidades). Para começar, a relação capital/produto nos exemplos de Furtado sempre pressupõe quantidades e preços dos elementos que compõem o numerador e o denominador; vale dizer, estão em questão os valores do capital e do produto, sendo difícil isolar 'quantidades' de fatores. O mesmo se estende às outras relações. Nessas condições, um aumento da densidade de capital (K/L), em condições de salários estáveis, tanto pode indicar variação dos elementos 'físicos' - quantidades de bens de capital por número de 
trabalhadores - quanto dos valores, em moeda nacional, assumidos pelo capital utilizado ${ }^{24}$. Como visto, o mesmo vale para a relação capital/produto, que reflete tanto relações físicas quanto o preço dos elementos que compõem os dois termos da razão. A taxa de lucro, por sua vez, reflete os valores (preços x quantidade) do capital e do produto, assim como a taxa salarial - esta sim, razoavelmente especificada (constante). Cabe relembrar que os preços, tanto do output quanto dos elementos do capital dos diversos segmentos da indústria, refletem as condições ditadas por taxas de câmbio específicas, proteções 'institucionais' de mercado, grau de monopólio... Em suma, difícil sermos precisos a respeito dos diversos coeficientes técnicos assumidos nas ilustrações numéricas explicitadas em Furtado (1966a). De todo modo, pela não identificação de coeficientes técnicos, não é conveniente inferirmos 'funções de produção'.

Vale lembrar que, em um modelo desenvolvido verbalmente, como o de Furtado, as ilustrações numéricas têm peso forte, pois funcionam como instrumentos para a racionalização do argumento. As ilustrações numéricas são decisivas para a exposição (e o entendimento) do modelo de estagnação. Quando Furtado (1966a) se refere a uma elevação da densidade do capital, ele tanto presume coeficientes técnicos - número de trabalhadores, quantidade de máquinas, produtividade física da mão-de-obra e do equipamento - quanto valores de salários, equipamentos, produto... E, como foi dito, a modelagem sempre se situa no terreno de preços relativos influenciados por um número ponderável de circunstâncias, inclusive taxa de câmbio. Quando menos pela impossibilidade de isolar coeficientes técnicos, eu hesitaria em dizer que funções de produção com substituibilidade de fatores determinam a hipótese estagnacionista; a qual, no entanto, depende crucialmente do (controverso) pressuposto de igualdade da taxa de lucro na indústria. Que tal pressuposto tenha sido na reexposição do texto de data bem posterior suprimido (Furtado (1973), não me parece casual.

\section{Referências bibliográficas}

ADELMAN, J. Wordly philosopher - The odyssey of Albert O. Hirschman. Princeton: Princeton UniversityPress, 2013.

BIANCHI, A. et al. América Latina: ensayos de interpretacióneconómica. Santiago, Editorial Universitaria, 1969.

BIANCONI, R. Estagnação latino-americana e estratégia brasileira de desenvolvimento: análises do início do exílio de Celso Furtado. In: ENCONTRO DA ABPHE, Vitória, 2015. Anais...

BOIANOVSKY, M. A formação política do Brasil segundo Furtado. Revista de Economia Politica, v. 34, n. 2, 2014.

(24) Na medida em que a taxa salarial é conhecida e não varia, L, que é um indicador de despesas salariais, permite identificar a quantidade de mão-de-obra empregada. 
Mauricio C. Coutinho

BUGELLI, A. H.; PIRES, J. M. Uma revisão da teoria da estagnação de Celso Furtado e a crise econômica dos anos 1960. Cadernos do Desenvolvimento, ano 6, n. 9, 2011.

CEPAL. Introdução à técnica de planejamento. In: BIELSCHOWSKY, R. Cinqüenta anos de pensamento na Cepal. Rio de Janeiro: Record, 2000.

CEPÊDA, V. A. O pensamento político de Celso Furtado: desenvolvimento e democracia. In: BRESSER-PEREIRA, L. C.; REGO, J. M. (Org.). A grande esperança em Celso Furtado. São Paulo: Editora 34, 2001.

COUTINHO, M. Celso Furtado e a crítica da teoria econômica. In: SABÓIA, João; CARDIM DE CARVALHO, Fernando J. (Org.). Celso Furtado e o século XXI. Barueri: Manole, 2007.

COUTINHO, M. Subdesenvolvimento e estagnação na América Latina, de Celso Furtado. Campinas, 2015. Mimeo.

FURTADO, C. A economia brasileira. Rio de Janeiro: Ed. A Noite, 1954.

FURTADO, C. Perspectivas da economia brasileira. Rio de Janeiro: Centro Internacional Celso Furtado de Políticas para o Desenvolvimento, [1958] 2012.

FURTADO, C. Formação econômica do Brasil. São Paulo: Companhia das Letras, [1959] 2009.

FURTADO, C. Desenvolvimento e subdesenvolvimento. Rio de Janeiro: Fundo de Cultura, 1961.

FURTADO, C. Political obstacles to economic growth in Brazil. International Affairs, London, v. 41, 1965a.

FURTADO, C. Development and stagnation in Latin America: a structuralist approach. Yale University Economic Growth Center, Yale, v. 1, n. 11, 1965b.

FURTADO, C. Subdesenvolvimento e estagnação na América Latina. Rio de Janeiro: Civilização Brasileira, 1966a.

FURTADO, C. Subdesarrollo y estagnación em América Latina. Desarrollo Económico, Buenos Aires, v. 6, n. 22-23, jul./dic. 1966b.

FURTADO, C. Teoria e política do desenvolvimento econômico. São Paulo: Companhia Editora Nacional, 1967.

FURTADO, C. Análise do modelo brasileiro. São Paulo: Civilização Brasileira, 1972.

FURTADO, C. A hegemonia dos Estados Unidos e o subdesenvolvimento da América Latina. Rio de Janeiro: Civilização Brasileira, 1973.

FURTADO, C. O mito do desenvolvimento econômico. Rio de Janeiro: Paz e Terra, 1974.

FURTADO, C. Prefácio a nova economia política. Rio de Janeiro: Paz e Terra, 1976. 
Furtado e seus críticos: da estagnação à retomada do crescimento econômico

FURTADO, C. Criatividade e dependência na civilização industrial. Rio de Janeiro: Paz e Terra, 1978.

FURTADO, C. A fantasia organizada. São Paulo: Paz e Terra, 1985.

FURTADO, C. A fantasia desfeita. São Paulo: Paz e Terra,1989.

FURTADO, C. Os ares do mundo. São Paulo: Paz e Terra, 1991.

FURTADO, C.; MANESCHI, A. Um modelo simulado de desenvolvimento e estagnaçao na América Latina. Revista Brasileira de Economia, Rio de Janeiro, FGV, v. 22, n. 2, 1968.

LEWIS, W.A. O desenvolvimento econômico com oferta ilimitada de mão de obra. In: AGARWALA, A. N.; SINGH, S. P. A economia do subdesenvolvimento. Rio de Janeiro: Contraponto, 2010.

NURKSE, R. Problems of capital formation in underdeveloped countries. Oxford: Basil Blackwell, 1953.

OLIVEIRA, F. Un clássico de El Trimestre Económico: Celso Furtado y el paradigma del subdesarrollo. El Trimestre Económico, Mexico, v. 50, n. 198 (2), 1983.

OLIVEIRA, F. Crítica à razão dualista. Estudos Cebrap, São Paulo, n. 2, 1972.

RODRIGUEZ, O. O estruturalismo latino-americano. Rio de Janeiro: Civilização Brasileira, 2009.

SALM, C. O debate sobre a tendência à estagnação. In: MALTA, M. (Org). Ecos do desenvolvimento - uma história do pensamento econômico brasileiro. Rio de Janeiro: Ipea/ Centro Celso Furtado, 2011.

TAVARES, M. C.; SERRA, J. Más allá del estancamento: una discusión sobre el estilo de desarrollo reciente. El Trimestre Económico, México, v. 38, n. 152 (4), p. 905-950, 1971.

TAVARES, M. C.; SERRA, J. Além da estagnação: uma discussão sobre o estilo de desenvolvimento recente. In: BIELSCHOWSKY, R. Cinqüenta anos de pensamento na Cepal. Rio de Janeiro: Record, 2000. 